\title{
COMMENTARY
}

\section{Is prolonged mechanical ventilation of cancer patients futile?}

Anne-Claire Toffart ${ }^{1,2^{*}}$ and Jean-François Timsit ${ }^{1,3}$

See related research by Shih et al., http://ccforum.com/content/17/4/R144

\begin{abstract}
The issue of limiting life-sustaining treatments for intensive care unit (ICU) patients is complex. The ethical principles applied by ICU staff when making treatment-limitation decisions must comply with the law of their country. Until 2011, the law in Taiwan prohibited the withdrawal of mechanical ventilation. Consequently, patients with severe underlying diseases could receive prolonged mechanical ventilation. In a study conducted by Shih and colleagues in patients with cancer in Taiwan, continuous mechanical ventilation for more than 21 days was associated with poor outcomes, particularly in the subgroups of patients with metastases, lung cancer, or liver cancer. These results highlight the need for appropriate legislation regarding the withdrawal of life-sustaining treatments in patients, especially those for whom no effective cancer treatments are available.
\end{abstract}

In the previous issue of Critical Care, Shih and colleagues [1] report the results of a claims database study in 5,138 cancer patients who received prolonged mechanical ventilation (PMV) in Taiwan between 1997 and 2007. The authors describe the incidence, outcomes, and prognostic factors of PMV in this cohort. PMV was defined as at least 21 days of continuous mechanical ventilation. Most of the patients survived the acute illness but required a disproportionate amount of health-care resources [2]. The incidences of PMV were 10.4 patients per 100 intensive care unit (ICU) admissions with cancer overall and 14.9 per 100 admissions of patients with lung

\footnotetext{
* Correspondence: atoffart@chu-grenoble.fr

'Université Grenoble 1 U 823-Institut A Bonniot-Université J Fourier - Rond point de la Chantourne, La Tronche Cedex, 38706, France

${ }^{2}$ Thoracic Oncology Unit, Teaching Hospital A Michallon, CHU de Grenoble CS 10217, Grenoble Cedex 09, 38043, France

Full list of author information is available at the end of the article
}

cancer. The prognosis was poor: 1-year survival rate was $14.3 \%$ ( $95 \%$ confidence interval $13.3 \%$ to $15.3 \%$ ). Survival rate and life expectancy were worse in the subgroups with metastases, lung cancer, or liver cancer. As previously reported, mortality was dependent mainly on metastatic status and acute organ failure (acute renal failure or shock). Moreover, quality-adjusted life expectancy (QALE) was poor, ranging from 0.18 to 0.48 qualityadjusted life-years (QALYs) in patients in the best cognitive-function category. The same team previously [3] estimated the cost of PMV at USD $\$ 64,708$ to USD $\$ 148,829$ per QALY for patients with cancer.

This study is original because it estimates the benefits of maximal treatment intensity in patients with cancer. In Taiwan, mechanical ventilation withdrawal, which may affect life expectancy [4], was illegal at the time of the study period. This is the first study on PMV for patients with cancer and the largest to investigate patients with cancer in the ICU. Furthermore, no previous data on outcomes of critically ill patients with different types of solid malignancies are available. Unlike in most other studies in critically ill patients with cancer, solid malignancies predominated (94\% of patients).

However, the data were extracted from a national health insurance database designed for cost evaluations and not for research purposes. A number of weaknesses of the study should be acknowledged. No data were available on the reason for ICU admission, severity of the acute disease, or performance status. Noninvasive mechanical ventilation and invasive mechanical ventilation were not distinguished from one another, and neither were intubation and tracheostomy. Furthermore, QALE was estimated by extrapolation from an external sample of 142 unselected ICU patients given PMV [3], and this fact may not be fully relevant to patients with cancer. The low QALE estimated for the first year was probably an underestimation of the overall quality of life during long-term survival, since quality of life has been reported to improve after 1 year in long-term survivors [5]. 
Little is known about the survival of patients with cancer treated with mechanical ventilation, particularly in those with solid malignancies. Differences have been reported according to the type of cancer. In lung cancer patients admitted to the ICU, 1-year survival was estimated to be $18 \%$ [6], versus $6.6 \%$ in the present study [1]. Mechanical ventilation for more than 96 hours affected quality of life and functional status but had no significant effect on survival in earlier studies $[7,8]$. In a multicenter hospital-discharge study in the US, mechanical ventilation for more than 96 hours, for any reason, resulted in higher hospital costs (USD \$40,903 versus USD \$14,434) with similar survival compared with shorter mechanical ventilation durations [8]. Similarly, among patients with cancer in a multicenter study from Brazil, including $91 \%$ given mechanical ventilation at ICU admission, hospital and 6-month mortality rates in those who spent more than 21 days in the ICU (50\% and $60 \%$, respectively) were similar to those in patients with shorter ICU stays (51\% and 61\%, respectively) [9]. In two other studies, no patients survived after being started on mechanical ventilation at least 3 days after ICU admission [10,11].

The prognostic factors in cancer patients admitted to the ICU are related to the history of the cancer, the condition of the patient, acute disease, and treatmentlimitation decisions $[4,12]$. The current evidence supports ICU admission of patients with cancer for a period of full-code management followed by a reappraisal of the situation after 3 to 5 days [13]. Thus, many studies have established that clinical deterioration during the first days of mechanical ventilation predicts futility of further mechanical ventilation [6,14]. Shih and colleagues [1] showed, in contrast, that stabilization or improvement after the first 3 days is not associated with higher mortality rates after PMV. However, PMV may result in a high risk of quality-of-life impairments. This point underlines the importance of having the patient and family participate in the treatment decisions.

Overall, PMV was beneficial in $14 \%$ of the cancer patients studied by Shih and colleagues [1]. However, the main characteristics of these patients are unknown. Further studies are warranted to determine which patients are likely to benefit from PMV according to their performance status, cancer history, and acute disease.

\section{Abbreviations}

ICU: Intensive care unit; PMV: Prolonged mechanical ventilation;

QALE: Quality-adjusted life expectancy; QALY: Quality-adjusted life-year

\section{Competing interests}

The authors declare that they have no competing interests.

\section{Author details}

'Université Grenoble 1 U 823-Institut A Bonniot-Université J Fourier - Rond point de la Chantourne, La Tronche Cedex, 38706, France. ${ }^{2}$ Thoracic Oncology Unit, Teaching Hospital A Michallon, CHU de Grenoble CS 10217,
Grenoble Cedex 09, 38043, France. ${ }^{3}$ Medical Intensive Care Unit, Teaching Hospital A Michallon, CHU de Grenoble CS 10217, Grenoble Cedex 09, 38043, France.

Published: 20 September 2013

\section{References}

1. Shih CY, Hung MC, Lu HM, Chen L, Huang SJ, Wang JD: Incidence, life expectancy, and prognostic factors in cancer patients under prolonged mechanical ventilation: a nation-wide analysis of 5,138 cases during 1998-2007. Crit Care 2013, 17:R144.

2. Carson SS: Outcomes of prolonged mechanical ventilation. Curr Opin Crit Care 2006, 12:405-411.

3. Hung MC, Lu HM, Chen L, Lin MS, Chen CR, Yu CJ, Wang JD: Cost per QALY (quality-adjusted life year) and lifetime cost of prolonged mechanical ventilation in Taiwan. PLoS One 2012, 7:e44043.

4. Azoulay E, Pochard F, Garrouste-Orgeas M, Moreau D, Montesino L, Adrie C, de Lassence A, Cohen Y, Timsit JF: Decisions to forgo life-sustaining therapy in ICU patients independently predict hospital death. Intensive Care Med 2003, 29:1895-1901.

5. Oeyen SG, Benoit DD, Annemans L, Depuydt PO, Van Belle SJ, Troisi RI, Noens LA, Pattyn P, Decruyenaere JM: Long-term outcomes and quality of life in critically ill patients with hematological or solid malignancies: a single center study. Intensive Care Med 2013, 39:889-898.

6. Toffart AC, Minet C, Raynard B, Schwebel C, Hamidfar-Roy R, Diab S, Quetant S, Moro-Sibilot D, Azoulay E, Timsit JF: Use of intensive care in patients with nonresectable lung cancer. Chest 2011, 139:101-108.

7. Douglas SL, Daly BJ, Gordon N, Brennan PF: Survival and quality of life: short-term versus long-term ventilator patients. Crit Care Med 2002, 30:2655-2662

8. Zilberberg MD, Luippold RS, Sulsky S, Shorr AF: Prolonged acute mechanical ventilation, hospital resource utilization, and mortality in the United States. Crit Care Med 2008, 36:724-730.

9. Soares M, Salluh JI, Torres VB, Leal JV, Spector N: Short- and long-term outcomes of critically ill patients with cancer and prolonged ICU length of stay. Chest 2008, 134:520-526.

10. Lecuyer L, Chevret S, Thiery G, Darmon M, Schlemmer B, Azoulay E: The ICU trial: a new admission policy for cancer patients requiring mechanical ventilation. Crit Care Med 2007, 35:808-814

11. Azoulay E, Thiéry G, Chevret S, Moreau D, Darmon M, Bergeron A, Yang K, Meignin V, Ciroldi M, Le Gall JR, Tazi A, Schlemmer B: The prognosis of acute respiratory failure in critically ill cancer patients. Medicine (Baltimore) 2004, 83:360-370.

12. Soares M, Caruso P, Silva E, Teles JM, Lobo SM, Friedman G, Dal Pizzol F, Mello PV, Bozza FA, Silva UV, Torelly AP, Knibel MF, Rezende E, Netto JJ, Piras C, Castro A, Ferreira BS, Réa-Neto A, Olmedo PB, Salluh Jl: Brazilian Research in Intensive Care Network (BRICNet): Characteristics and outcomes of patients with cancer requiring admission to intensive care units: a prospective multicenter study. Crit Care Med 2010, 38:9-15.

13. Azoulay E, Soares M, Darmon M, Benoit D, Pastores S, Afessa B: Intensive care of the cancer patient: recent achievements and remaining challenges. Ann Intensive Care 2011, 1:5

14. Groeger JS, Glassman J, Nierman DM, Wallace SK, Price K, Horak D, Landsberg D: Probability of mortality of critically ill cancer patients at 72 h of intensive care unit (ICU) management. Support Care Cancer 2003, 11:686-695. 